Jurnal Psikologi Malahayati, Volume 1, No.1, Maret 2019: 35-40

\title{
HUBUNGAN TINGKAT STRES DENGAN KEJADIAN DISMINOREA PADA MAHASISWI KEDOKTERAN di UNIVERSITAS MALAHAYATI BANDAR LAMPUNG
}

\author{
Vira Sandayanti' ${ }^{1}$ Ade Utia Detty², Jemino³ \\ 1Program Studi Psikologi, FK Universitas Malahayati, Bandar Lampung. Email: virasanda@malahayati.ac.id \\ 2Program Studi Pendidikan Dokter, FK Universitas Malahayati, Bandar Lampung. \\ ${ }_{3}^{3}$ Program Studi Pendidikan Dokter, FK Universitas Malahayati, Bandar Lampung. Email: jeminosri92@gmail.com
}

\section{ABSTRACT: RELATIONSHIP BETWEEN STRESS LEVEL AND DYSMENORRHOEA INCIDENTS IN MEDICAL STUDENTS OF MALAHAYATI UNIVERSITY BANDAR LAMPUNG YEAR 2017.}

Introduction: Dysmenorrhoea is a pain in the pelvic area due to menstruation and prostaglandin substance production. One of the causes of dysmenorrhoea is stress. Stress is a physiological, psychological and behavioral response of humans who try to adapt and manage.

Purpose: This study aimed to find relationship between stress level and dysmenorrhoea incidents in college students Method: This study is observational analytic research with cross sectional design. Sample of this study is 178 college students obtained from convenience sampling. The data analysis using pearson correlation.

Result : The result showed that there was a relationship between stress level and incidence of dysmenorrhoea $p$ value $=0,029(p<0,05)$ with $r=0,704$.

Summary: The conclusion of this study is the relationship between stress level and incidence of dysmenorrhoea in medical student grade 2017 at University Malahayati Bandar Lampung.

Keywords: Medical Students, Stress, Dysmenorrhoea.

Pendahuluan : Dismenorea adalah nyeri pada daerah panggul akibat menstruasi dan produksi zat prostaglandin. Salah satu penyebab dismenorea adalah stres. Stres merupakan suatu respon fisiologis, psikologis dan perilaku dari manusia yang mencoba untuk mengadaptasi dan mengatur baik tekanan internal dan eksternal.

Tujuan: Penelitian ini bertujuan untuk melihat hubungan antara tingkat stress dengan kejadian disminorea pada mahasiswi.

Metode : Penelitian ini merupakan penelitian observasi analitik dengan pendekatan cross sectional. Sampel penelitian berjumlah 178 mahasiswa yang diperoleh dengan convenience sampling. Analisa data hasil penelitian menggunakan korelasi Pearson.

Hasil : Hasil penelitian menunjukkan bahwa ada hubungan antara stres dengan kejadian disminorea $p$-value $=0,029$ $(p<0,05)$ dengan $r=0,704$.

Simpulan : Kesimpulan dari penelitian ini adalah terdapat hubungan antara tingkat stres dengan kejadian disminorea pada pada mahasiswi kedokteran angkatan 2017 di Universitas Malahayati Bandar Lampung tahun 2017.

Kata Kunci : Mahasiswi, Stres, Disminorea

\section{PENDAHULUAN}

Menstruasi merupakan salah satu proses perubahan yang terjadi pada masa pubertas yang menandai kematangan organ reproduksi. Menstruasi adalah perdarahan secara periodik dan siklik dari uterus yang disertai pelepasan (deskuamasi) endometrium. Berbagai masalah yang timbul pada menstruasi merupakan masalah ginekologi yang sering dikeluhkan pada remaja, seperti ketidakteraturan menstruasi, menoragia, dismenorea, dan gejala lain yang berhubungan (Singh, Kiran, Nel \& Tiwari, 2008; Irianti, 2018; Setiawati, 2015).
Dismenorea adalah nyeri pada daerah panggul akibat menstruasi dan produksi zat prostaglandin. Seringkali dimulai setelah mengalami haid pertama (menarche). Nyeri berkurang setelah menstruasi, namun pada beberapa wanita nyeri bisa terus dialami selama periode menstruasi, terdapat dua jenis dismenorea yang terdiri dari dismenorea primer dan dismenorea sekunder (Hacker, Moore \& Gambone, 2004; Novia, Puspitasari, 2008; Lestari, 2013).

Menurut WHO angka dismenore di dunia sangat besar, rata-rata lebih dari $50 \%$ perempuan di 
setiap Negara mengalami dismenore. Di Swedia sekitar $72 \%$. Prevalensi dismenorea di Indonesia tahun 2008 sebesar $64,25 \%$ yang terdiri dari $54,89 \%$ dismenorea primer dan 9,36\% dismenorea sekunder. Menurut data Dinkes Provinsi Lampung didapatkan sebesar 1,07-1,31\% dari jumlah kunjungan ke bagian kebidanan adalah penderita dismenore, dilaporkan $30-60 \%$ remaja wanita yang mengalami dismenore, sebanyak $7-15 \%$ tidak pergi ke sekolah atau bekerja (Novia \& Puspitasari, 2008; Ulfa \& Hidayat, 2015; RIDK, 2010).

Tingkat insiden tertinggi dismenorea terjadi pada perempuan yang mempunyai tingkat stres sedang hingga tinggi dibanding dengan perempuan yang mempunyai tingkat stres rendah. Dismenorea yang terjadi pada perempuan dengan tingkat stres rendah sebesar $22 \%$, dengan tingkat stres sedang $29 \%$ dan perempuan dengan tingkat stres tinggi sebesar 44\% (Wangsa, 2010; Saputri, 2011).

Salah satu penyebab dismenorea adalah faktor psikis, faktor psikis tersebut adalah stres . Stres merupakan suatu respon individu terhadap keadaan atau kejadian yang dapat mengancam dan mengganggu kemampuan seseorang untuk menanganinya . Stres dapat mengganggu kerja sistem endokrin sehingga dapat menyebabkan menstruasi yang tidak teratur dan rasa sakit saat menstruasi atau dismenorea (Wijayanti, 2009; Santrock \& Santrock, 2008; Hawari, 2008).

Stres merupakan suatu respon fisiologis, psikologis dan perilaku dari manusia yang mencoba untuk mengadaptasi dan mengatur baik tekanan internal dan eksternal. Stres yang berkelanjutan dapat menyebabkan depresi. Faktor-faktor yang menyebabkan stres berasal dari rangsangan fisik, psikologis, atau dapat keduanya. Stres fisik disebabkan oleh exposure stresor yang berbahaya bagi jaringan tubuh misalnya terpapar pada keadaan dingin atau panas, penurunan konsentrasi oksigen, infeksi, luka/injuries, latihan fisik yang berat dan lama, dll. Sedangkan pada stres psikologis misalnya pada perubahan kehidupan, hubungan sosial, perasaan marah, takut, depresi (Sherwood, 2007; Jahja, 2011).

Berdasarkan data hasil pre-survey yang dilakukan kepada beberapa mahasiswi di Fakultas Kedokteran Universitas Malahayati Bandar Lampung, waktu dilakukan wawancara diketahui beberapa mahasiswi saat sedang menstruasi mahasiswi tersebut mengalami disminorea, hal ini membuat mereka tidak dapat menyesuaikan diri dalam belajar seperti konsentrasi tergangu, hingga akhirnya mahasiswi tersebut tidak mampu belajar dengan baik, maka dapat dikatakan bahwa mahasiswi tersebut mengalami stres, hal ini sesuai dengan teori yang dikatakan oleh Nevid bahwa stres merupakan suatu tekanan yang muncul karena tingginya tekanan dan ketegangan, sehingga orang tersebut tidak mampu beradaptasi atau menyesuaikan diri. Hal ini didukung oleh penelitian dengan judul hubungan Stres dengan Kejadian Dismenore Primer pada Mahasiswi Pendidikan Dokter Fakultas Kedokteran Universitas Andalas dengan hasil ada hubungan yang bermakna dengan korelasi agak lemah antara tingkat stres dengan derajat dismenore primer (Nevid, Rathus \& Greene, 2005; Sari, Nurdin \& Defrin, 2015).

\section{METODE PENELITIAN}

Penelitian ini merupakan penelitian kuantitatif dengan design penelitian observasional analitik dengan pendekatan potong lintang (cross sectional). Teknik pengambilan sampel menggunakan metode convenience sampling dan diperoleh 178 sampel mahasiswi kedokteran Universitas Mahalayati angkatan 2017. Sampel tersebut akan diseleksi berdasarkan kriteria inklusi, yaitu bersedia menjadi peserta penelitian dan memiliki siklus menstruasi yang teratur; serta kriteria eksklusi yaitu memiliki penyakit atau riwayat penyakit ginekologi (anomaly organ kewanitaan, servisitis, keputihan,trichomoniasis, dil.). Data penelitian diperoleh menggunakan kuesioner perceived stress scale (PSS-10) dan wawancara singkat. Uji statistik yang digunakan yaitu uji Pearson

Vira Sandayanti ${ }^{1}$ Program Studi Psikologi, FK Universitas Malahayati, Bandar Lampung. Email: virasanda@malahayati.ac.id

Ade Utia Detty² Program Studi Pendidikan Dokter, FK Universitas Malahayati, Bandar Lampung.

Jemino $^{3}$ Program Studi Pendidikan Dokter, FK Universitas Malahayati, Bandar Lampung. Email: jeminosri92@gmail.com 
HUBUNGAN TINGKAT STRES DENGAN KEJADIAN DISMINORE PADA MAHASISWA KEDOKTERAN UNIVERSITAS BANDAR LAMPUNG

HASIL

Tabel 1. Distribusi Frekuensi Usia Responden.

\begin{tabular}{ccc}
\hline Usia & Frekuensi & Persentase (\%) \\
\hline 16 Tahun & 2 & 1.1 \\
17 Tahun & 14 & 7.9 \\
18 Tahun & 13 & 7.3 \\
19 Tahun & 29 & 16.3 \\
20 Tahun & 57 & 32.0 \\
21 Tahun & 25 & 14.0 \\
22 Tahun & 38 & 21.3 \\
\hline Total & 178 & 100.0 \\
\hline
\end{tabular}

Berdasarkan tabel 1 dapat dilihat sebagian besar responden berusia 20 tahun ( $32 \%$ ) dan paling sedikit berusia 16 tahun $(1,1 \%)$.

Tabel 2. Distribusi Frekuensi Karakteristik Responden Berdasarkan Usia Menarche Responden.

\begin{tabular}{ccc}
\hline Usia Menarche & Frekuensi & Persentase $(\%)$ \\
\hline 10 Tahun & 15 & 8.4 \\
11 Tahun & 23 & 12.9 \\
12 Tahun & 51 & 28.7 \\
13 Tahun & 45 & 25.3 \\
14 Tahun & 40 & 22.5 \\
15 Tahun & 4 & 2.2 \\
\hline Total & 178 & 100.0 \\
\hline
\end{tabular}

Berdasarkan tabel 2 ditemukan bahwa sebagian besar responden memiliki usia menarche 12 tahun $(28,7 \%)$ dan paling sedikit berusia menarche 15 tahun $(2,2 \%)$.

Tabel 3. Distribusi Frekuensi Responden Berdasarkan Tingkat Stres Responden

\begin{tabular}{lcc}
\hline Tingkat Stres & Frekuensi & Persentase (\%) \\
\hline Stres Ringan & 154 & $86.5 \%$ \\
Stres Sedang & 6 & $3.4 \%$ \\
Stres Berat & 18 & $10.1 \%$ \\
\hline Total & $\mathbf{1 7 8}$ & $\mathbf{1 0 0} \%$
\end{tabular}

Berdasarkan tabel 3 ditemukan bahwa sebagian besar responden mengalami stress ringan $(86,5 \%)$ dan paling sedikit mengalami stress sedang $(3,4 \%)$. Selanjutnya, distribusi responden berdasarkan disminorea, didapatkan jumlah disminore berjumlah 177 responden (99.4\%) dan jumlah tidak disminore berjumlah 1 responden (0.6\%).

Penelitian ini menggunakan PSS-10 untuk mengukur stress. PSS-10. dalam bahasa Indonesia, telah diuji dan memiliki nilai koefisien cronbach alpha sebesar 0,96 . Variabel berskala numerik yang telah diperoleh dari PSS-10 kemudian diubah menjadi skala ordinal dengan titik potong tertentu menjadi 3 kelompok: (1) Stres ringan, total skor 013; (2) Stres sedang, total skor 14-26; dan (3) Stres berat, total skor 27-40 (Cohen, Kamarack \& Mermelstein, 1983; Bhat, Sameer \& Ganaraja., 2011).

Vira Sandayanti ${ }^{1}$ Program Studi Psikologi, FK Universitas Malahayati, Bandar Lampung. Email: virasanda@malahayati.ac.id

Ade Utia Detty2 Program Studi Pendidikan Dokter, FK Universitas Malahayati, Bandar Lampung.

Jemino 3 Program Studi Pendidikan Dokter, FK Universitas Malahayati, Bandar Lampung. Email: jeminosri92@gmail.com 
HUBUNGAN TINGKAT STRES DENGAN KEJADIAN DISMINORE PADA MAHASISWA KEDOKTERAN UNIVERSITAS BANDAR LAMPUNG

Tabel 4. Hubungan antara Tingkat Stres dengan Kejadian Disminorea pada Responden.

\begin{tabular}{|c|c|c|c|c|c|c|}
\hline \multirow{3}{*}{$\begin{array}{c}\text { Kategori } \\
\text { Stres }\end{array}$} & \multicolumn{4}{|c|}{ Disminorea } & \multirow{3}{*}{$\begin{array}{c}p- \\
\text { value }\end{array}$} & \multirow{3}{*}{ r } \\
\hline & \multicolumn{2}{|c|}{$\mathrm{Ya}$} & \multicolumn{2}{|r|}{ Tidak } & & \\
\hline & $n$ & $\%$ & $\mathrm{n}$ & $\%$ & & \\
\hline $\begin{array}{l}\text { Stres } \\
\text { ringan }\end{array}$ & 153 & $86.5 \%$ & 1 & $100.0 \%$ & & \\
\hline $\begin{array}{l}\text { Stres } \\
\text { sedang }\end{array}$ & 6 & $3.4 \%$ & 0 & $0.00 \%$ & 0,029 & 0,704 \\
\hline $\begin{array}{l}\text { Stres } \\
\text { berat }\end{array}$ & 18 & $10.1 \%$ & 0 & $0.00 \%$ & & \\
\hline Total & 177 & $100 \%$ & 1 & $100 \%$ & & \\
\hline
\end{tabular}

Berdasarkan hasil uji statistik, diperoleh nilai Pearson hitung dengan $(p=0,029<p=0,05)$, hal ini menunjukkan terdapat hubungan antara tingkat stres dengan kejadian disminorea pada pada mahasiswi kedokteran angkatan 2017 di Universitas Malahayati Bandar Lampung tahun 2017. Kekuatan Korelasi (r) didapatkan 0,704 artinya, tingkat kekuatan hubungan (korelasi) antara variabel stres dengan kejadian disminorea adalah sebesar 0,704 atau kuat. dengan nilai positif, yaitu 0,704 sehingga hubungan kedua variabel tersebut bersifat searah (jenis hubungan searah), dengan demikian dapat diartikan bahwa tingkat stres makin tinggi maka kejadian disminorea juga akan meningkat.

\section{PEMBAHASAN}

Berdasarkan hasil penelitian diatas didapatkan 18 responden yang mengalami stres berat saat dismenorea, sehingga hal ini cukup menjadi perhatian bagi peneliti, apakah yang membuat mahasiswi stres berat itu hanya faktor dismenorea atau ada faktor lainnya, wanita pada umumnya saat mengalami dismenorea hanya mengalami stres ringan dan jarang sampai mengalami stres berat. Menurut teori ada beberapa faktor yang dapat memperparah stres seorang wanita yang sedang mengalami dismenorea seperti faktor psikologis, pada wanita remaja (mahasiswi angkatan 2017) secara emosional masih belum stabil, hal ini disebabkan oleh ketidakpahaman mereka akan proses haid. Selain itu ketika mereka sedang mengalami dismenorea sangatlah rentan menghadapi ketegangan yang mereka alami di rumah dan sekolah, sehingga keadaan ini dapat memperburuk tingkat stres nya. (Sari, Indrawati, Basuki, 2012; Priyanti \& Mustikasari, 2015 ).

Hasil penelitian ini sejalan dengan penelitian yang dilakukan oleh Susanti, hasil penelitian diketahui mayoritas stres pada mahasiswi DIII kebidanan semester II dalam kategori sedang (yaitu 74,4\%). Kejadian dismenorea dalam kategori sedang juga sebanyak $(71,2 \%)$, ada hubungan stres dengan kejadian dismenorea pada mahasiswi DIII kebidanan semester II di stikes "aisyiyah yogyakarta, dibuktikan dengan nilai signikasi $(p<0,05)$. Nilai korelasi kendal tau sebesar 0,450 artinya hubungan antar variabel memiliki tingkat keeratan dalam kategori sedang. (Susanti, 2014).

Hasil penelitian ini didukung dengan teori yang menyatakan bahwa terdapat hubungan antara tingkat stres dengan kejadian disminorea, Saat seseorang mengalami stres terjadi respon neuroendokrin, sehingga menyebabkan Corticotrophin Releasing Hormone (CRH) yang merupakan regulator hipotalamaus utama menstimulasi sekresi Adrenocorticotrophic Hormone (ACTH). ACTH akan meningkatkan sekresi kortisol adrenal. Hormonhormon tersebut menyebabkan sekresi Follicle Stimulating Hormone (FSH) dan Luteinizing Hormone (LH) terhambat sehingga perkembangan folikel terganggu. Hal ini menyebabkan sintesis dan pelepasan progesteron terganggu. Kadar progesteron yang rendah meningkatkan sintesis prostaglandin $F_{2 a ́}$ dan $E_{2}$. Ketidakseimbangan antara prostaglandin $F_{2 a ́}$ dan $\mathrm{E}_{2}$ dengan prostasiklin $\left(\mathrm{PGI}_{2}\right)$ menyebabkan

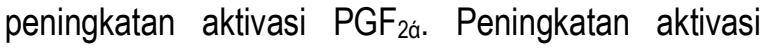
menyebabkan iskhemia pada sel-sel miometrium dan peningkatan kontraksi uterus. Peningkatan kontraksi yang berlebihan menyebabkan dismenorea

Vira Sandayanti ${ }^{1}$ Program Studi Psikologi, FK Universitas Malahayati, Bandar Lampung. Email: virasanda@malahayati.ac.id

Ade Utia Detty² Program Studi Pendidikan Dokter, FK Universitas Malahayati, Bandar Lampung.

Jemino $^{3}$ Program Studi Pendidikan Dokter, FK Universitas Malahayati, Bandar Lampung. Email: jeminosri92@gmail.com 
HUBUNGAN TINGKAT STRES DENGAN KEJADIAN DISMINORE PADA MAHASISWA KEDOKTERAN UNIVERSITAS BANDAR LAMPUNG

(Wulandari, Hadisaputro \& Runjati, 2016; Lestari, 2013).

\section{SIMPULAN DAN SARAN}

Berdasarkan hasil penelitian dapat disimpulkan ada hubungan yang bermakna antara tingkat stress dan kejadian disminorea pada mahasiswi. Sebagian bsar mahasiswa mengalami stress ringan dan mengalami disminorea. Institusi pendidikan dalam hal ini Universitas Malahayati diharapkan dapat melakukan pembinaan agar mahasiswi dapat mengatasi stres yang timbul sehingga dapat mengurangi munculnya kejadian disminorea. Lebih lanjut peneliti selanjutnya, diharapkan agar memperhatikan variabel lain sebagai variabel pengganggu karena kekuatan korelasi yang didapatkan sangat signifikan dan pada penelitian ini hanya dilakukan analisis bivariate yang menemukan hubungan tidak murni, agar didapatkan hubungan yang murni maka dapat dilakukan analisis multivariate di penelitian selanjutnya.

\section{DAFTAR PUSTAKA}

Bhat, R. M., Sameer, M. K., \& Ganaraja, B. (2011). Eustress in education: Analysis of the perceived stress score (PSS) and blood pressure (BP) during examinations in medical students. Journal of clinical and diagnostic research, 5(7), 331-1335.

Cohen, S., Kamarck, T., \& Mermelstein, R. (1983). A global measure of perceived stress. Journal of health and social behavior, 385-396.

Hacker, N., Moore, J. G., \& Gambone, J. (2004). Essentials of Obstetrics and Gynecology. vol. 1.

Hawari, D. (2008). Manajemen Stres Cemas dan Depresi Balai Penerbit FKUI.

Irianti, B. (2018). FAKTOR-FAKTOR YANG MEMPENGARUHI KEJADIAN DISMENORE PADA REMAJA. Menara IImu, 12(10).
Jahja, Y. (2011). Psikologi perkembangan. Kencana.

Lestari, N. M. S. D. (2013, December). Pengaruh dismenorea pada remaja. In Prosiding Seminar Nasional MIPA.

Nevid, J. S., Rathus, S. A., \& Greene, B. (2005). Psikologi abnormal. Jakarta: Erlangga, 96-101.

Novia, I., \& Puspitasari, N. (2008). Faktor risiko yang mempengaruhi kejadian Dismenore Primer. The Indonesian Journal of Public Health, 4(3).

Priyanti, S., \& Mustikasari, A. D. (2015). Hubungan Tingkat stres Terhadap Dismenore pada Remaja putri di madrasah aliyah mamba'ul ulum Awang-Awang mojosari mojokerto. Hospital Majapahit, 6(2).

RI, D. K. (2010). Angka Kejadian Dismenore. Jakarta: Direktorat Jenderal Bina Kesehatan Masyarakat.

Santrock, J. W., \& Santrock, J. W. (2008). Life span development: A topical approach to. McGraw-Hill.

Saputri, M. I. D. (2011). Hubungan Antara Stres Dengan Kejadian Dismenorea Pada Siswi SMK N 1 Karanganyar (Doctoral dissertation, Universitas Sebelas Maret).

Sari, D., Nurdin, A. E., \& Defrin, D. (2015). Hubungan Stres dengan Kejadian Dismenore Primer pada Mahasiswi Pendidikan Dokter Fakultas Kedokteran Universitas Andalas. Jurnal Kesehatan Andalas, 4(2).

Sari, W., Kes, M., Indrawati, L., Kes, M., \& Basuki Dwi Harjanto, M. M. (2012). Panduan lengkap kesehatan wanita. Penebar PLUS+.

Setiawati, S. E. (2015). Pengaruh stres terhadap siklus menstruasi pada remaja. Jurnal Majority, 4(1).

Sherwood, L. (2007). Human Physiology: From Cells to Systems. Singapore: Cengage Learning Asia. Diterjemahkan oleh BU Pendit. 2009. Fisiologi Manusia: Dari Sel ke Sistem.

Vira Sandayanti ${ }^{1}$ Program Studi Psikologi, FK Universitas Malahayati, Bandar Lampung. Email: virasanda@malahayati.ac.id

Ade Utia Detty² Program Studi Pendidikan Dokter, FK Universitas Malahayati, Bandar Lampung.

Jemino $^{3}$ Program Studi Pendidikan Dokter, FK Universitas Malahayati, Bandar Lampung. Email: jeminosri92@gmail.com 
Singh, A., Kiran, D., Singh, H., Nel, B., Singh, P., \& Tiwari, P. (2008). Prevalence and severity of dysmenorrhea: a problem related to menstruation, among first and second year female medical students. Indian J Physiol Pharmacol, 52(4), 389-397.

Susanti, E. (2014). Hubungan Stres dengan Kejadian Dismenorea pada Mahasiswa DIII Kebidanan Semester II di Stikes' Aisyiyah Yogyakarta Tahun 2014 (Doctoral dissertation, STIKES'Aisyiyah Yogyakarta).

Ulfa, T. F., \& Hidayat, A. (2015). Pengaruh Senam Dysmenorhea Terhadap Skala Nyeri Dysmenorhea Pada Remaja Putri Di SMP Ali Maksum Yogyakarta Tahun 2015 (Doctoral dissertation, STIKES'Aisyiyah Yogyakarta).

Wangsa, T. (2010). Menghadapi Stres dan Depresi. Jakarta Selatan. Oryza.

Wijayanti, D. (2009). Fakta penting seputar kesehatan reproduksi wanita. Book Marks. Jogjakarta

Wulandari, E., Hadisaputro, S., \& Runjati, R. (2016). Pengaruh Abdominal Stretching Exercise Terhadap Penurunan Kadar Prostaglandin Pada Dismenore Primer (Doctoral dissertation, School of Postgraduate).

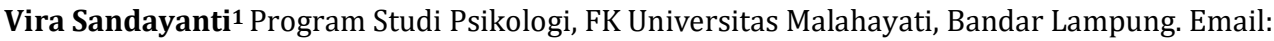
virasanda@malahayati.ac.id

Ade Utia Detty² Program Studi Pendidikan Dokter, FK Universitas Malahayati, Bandar Lampung.

Jemino $^{3}$ Program Studi Pendidikan Dokter, FK Universitas Malahayati, Bandar Lampung. Email: jeminosri92@gmail.com 